\title{
OBITUARY
}

\section{JOHN WHARTON}

We regret to record the death of Dr. John Wharton, which occurred at his home in Cheshire on May 5 last, after a short illness, at the age of 75 years.

John Wharton had a distinguished academic career. He was elected a foundation scholar and a Hare's exhibitioner at St. John's College, Cambridge, graduating B.A. with first class honours in 1898. He continued his medical education at Owen's College, Manchester, obtaining the Cambridge degrees of B.Chir. in 1902 and M.B. in 1903, subsequently proceeding to M.A. and M.D. After a period as house surgeon to the late Sir William Thorburn, he was appointed in 1904 as junior house surgeon to the Manchester Royal Eye Hospital. Thus began a life-long connection with this institution, as he became successively assistant-honorary, honorary, and consulting surgeon, and was ultimately appointed a vice-president of the hospital. In 1923 he was elected honorary ophthalmic surgeon to the Manchester Royal Infirmary, an appointment which made him directly responsible for the clinical training of students: at this time he also became clinical lecturer in ophthalmology at the University of Manchester.

For many years Dr. Wharton was an active member of the Ophthalmological Society of the United Kingdom; he was a foundation member of the North of England Ophthalmological Society, though he resigned in 1923 on a matter of principle. Not a prolific writer, he produced an outstanding monograph on ophthalmia neonatorum and was largely responsible for the establishment of a special segregated unit at his hospital for the treatment of this, then, serious condition.

" J. W." was one of the great triumvirate of clinicians of the last generation at the Manchester Royal Eye Hospital-Gray Clegg, Horsman McNabb, John Wharton. All were outstanding, but possibly Wharton had the most balanced judgment. He was superb on a difficult fundus: sound, always with reasons for his opinion, and rarely wrong. He was an excellent teacher, for he possessed a logical, clear-cut mind, and could interpret his subject in simple terms understandable to all. As an operator, some might say, of the old school, he was first class, making surgery look easy by his dexterity and simplicity of handling. In committee, he was shrewd and balanced and could see a problem in its right perspective: it is a misfortune for ophthalmology that he was unable to participate in all the planning which has been so necessary since the implementation of the National Health Service Act, for his advice and guidance would have been invaluable.

" J. W." was a loyal and affectionate colleague; he had the highest of ethical standards and nothing would alter his views if he believed them to be right. Sometimes this attitude was misunderstood, but when it became appreciated, it made those with whom, he came in contact all the more aware of his fine character. He had many friends, all of whom are the richer for their association with him.

O. M. D. 